\title{
Criminalização dos efeitos tradicionais da pesca artesanal em Santa Catarina: notas sobre duas situações de perícia antropológica
}

\author{
Anahi Guedes Mello \\ Doutoranda em Antropologia Social \\ Universidade Federal de Santa Catarina \\ Gabriela Cardoso Ribeiro \\ Mestre em Sociologia Política \\ Universidade Federal de Santa Catarina \\ Marcos Farias Almeida \\ Doutor em Antropologia Social UFSC \\ Ministério Público Federal em Santa Catarina - MPF/SC
}

\begin{abstract}
Resumo: A criminalização da pesca artesanal nos municípios catarinenses de Governador Celso Ramos e Florianópolis, a partir da experiência de atuação da equipe de Antropologia do Ministério Público Federal em Santa Catarina, é o objeto desta reflexão. A tradicionalidade da ocupação de ranchos de pesca em determinado território verifica-se pela realização de perícia antropológica para caracterizar os modos de vida dos pescadores locais. Os laudos periciais antropológicos mostram que a ação do MPF/SC é processada num contexto de marginalização da tradicionalidade, de conflitualidade que perpassa a legislação ambiental, os diversos órgãos públicos e o código penal, os quais operam sem considerar as especificidades da pesca artesanal. As denúncias desses órgãos recorrentemente não consideram os efeitos das identidades étnicas em jogo e pautam-se em um conceito de meio ambiente que coloca em risco os interesses das populações tradicionais, garantidos desde a Constituição de 1988.
\end{abstract}

Palavras-chave: Pesca artesanal; Populações tradicionais; Meio ambiente;Território; Laudos periciais. 


\title{
Criminalization of the traditional effects of artisanal fisheries practices in Santa Catarina, Brazil: notes on two situations of anthropological assessments
}

\begin{abstract}
Researchers from the Anthropology unit of the Federal Public Ministry in Santa Catarina (MPF/SC) document the criminalization of artisanal fisheries in Governador Celso Ramos and Florianópolis, cities located in State of Santa Catarina, Brazil. Anthropological assessments document the lifestyle of local fisherman and verify the traditional nature of how fishing ranches occupy set territory. Anthropological reports show that, in failing to consider the specificities of the artisanal fishing, the actions of the MPF/SC, through the environmental legislation, the various public entities, and the penal code, all to operate marginalize traditional practices, resulting in conflicts. The denunciations made by these public bodies do not consider the ethnic identities at stake and are based on a concept of the environment that endangers the interests, guaranteed in the 1988 Federal Constitution, of traditional populations.
\end{abstract}

Keywords: Artisanal fishing; Traditional populations; Environment; Territory; Anthropological reports.

\section{La criminalización de los efectos tradicionales de la pesca artesanal en Santa Catarina, Brasil: notas sobre dos situaciones de pericia antropológica}

Resumen: El objeto de esta reflexión es la criminalización de la pesca artesanal en Governador Celso Ramos y Florianópolis, dos ciudades situadas en la provincia de Santa Catarina, Brasil, basado en la experiencia de acción del equipo de Antropología del Ministerio Público de Santa Catarina. La tradicionalidad de la ocupación de los ranchos de pesca en un determinado territorio se produce a través de la realización de pericia antropológica para caracterizar los estilos de vida de los pescadores locales. Los informes periciales antropológicos muestran que la acción del MPF/SC se procesa en un contexto de marginación de la tradicionalidad, de conflictividad corriendo a través de la legislación ambiental, los diversos organismos públicos y el código penal, todos ellos operando sin tener en cuenta las especificidades de la pesca artesanal. Las denuncias de esos órganos públicos recurrentemente no tienen en cuenta los efectos de las identidades étnicas en juego y son guiados por un concepto de medio ambiente que pone en peligro los intereses de las poblaciones tradicionales, garantizados por la Constitución Federal de 1988.

Palabras clave: Pesca artesanal; Poblaciones tradicionales; Medio ambiente; Territorio; Informes periciales antropológicos. 


\section{Introdução}

A criminalização dos efeitos tradicionais da pesca artesanal, a partir da experiência de atuação da equipe de Antropologia da Assessoria Pericial do Ministério Público Federal em Santa Catarina (MPF/SC), é o objeto desta reflexão. Toma-se como ponto de partida dois processos judiciais analisados pela equipe de profissionais da área de Antropologia do MPF/SC nos anos de 2009 a 2010, com o intuito de verificar, através de análise antropológica, a tradicionalidade da ocupação de ranchos de pesca por pescadores artesanais em área de restinga/faixa de areia da Praia das Cordas, localizada no município de Governador Celso Ramos, e da Praia da Tapera, no município de Florianópolis, ambos no Estado de Santa Catarina. Pretende-se subsidiar as ações do Ministério Público Federal oficiadas no interesse de inquéritos policiais civis (IPLs) para apurar a autoria e materialidade de crime ambiental previsto no Art. 64 da Lei no 9.605/98, que versa "sobre as sanções penais e administrativas derivadas de condutas e atividades lesivas ao meio ambiente, e dá outras providências”. Em suma, o Art. 64 dessa lei considera crime contra o ordenamento urbano e patrimônio cultural:

\footnotetext{
Promover construção em solo não edificável, ou no seu entorno, assim considerado em razão de seu valor paisagístico, ecológico, artístico, turístico, histórico, cultural, religioso, arqueológico, etnográfico ou monumental, sem autorização da autoridade competente ou em desacordo com a concedida [...]. (BRASIL, 1998)
}

Existem diversos processos judiciais instaurados pela polícia ambiental do Estado de Santa Catarina que denunciam os pescadores que possuem ranchos de pesca em Área de Preservação Permanente (APP). Por exemplo, somente em relação à Praia de Ponta das Canas ${ }^{1}$, em Florianópolis, fomos acionados, no ano de 2010, em cinco processos envolvendo pescadores desse local. Ao invés de desenvolvermos um parecer técnico sobre os cinco casos de forma separada, elaboramos um único laudo pericial que contemplou as entrevistas e fotografias realizadas em duas saídas de campo, tratando da tradicionalidade da pesca na região com a preocupação de caracterizar esta prática e apontar para esse processo de criminalização da pesca artesanal.

Segundo Leite Lopes (2006: 36), a questão ambiental tem emergido como uma "nova fonte de legitimidade e de argumentação nos conflitos", presentes em diversos contextos sociopolíticos, tais como aqueles permeados pelas atividades de pesca artesanal. As práticas de pesca artesanal registradas para efeito de aplicação legal, inclusive como dispõe o Decreto Federal 6.040/2007, que "institui a Política Nacional de Desenvolvimento Sustentável dos Povos e Comunidades Tradicionais", devem ser caracterizadas em consideração aos modos de vida das populações locais que realizam atividades tradicionais, 
sobretudo, quando elas estão imbricadas em um quadro de processos que envolvem a ambientalização ${ }^{2}$ dos conflitos sociais. Em resenha crítica on line, Barretto Filho (2005) resume e corrobora o excelente trabalho coordenado por Leite Lopes, referindo-se ao processo de ambientalização como "um neologismo construído por homologia a outros usados nas Ciências Sociais, tais como industrialização e proletarização", sendo a ambientalização compreendida de duas maneiras: a primeira como um "processo de constituição de uma questão coletiva e pública, a "questão ambiental", que emerge comofonte de legitimação e argumentação nos conflitos sociais"; a segunda, como "interiorização de comportamentos e práticas por meio da promoção da educação ambiental". Por isso, "o uso de referenciais conceituais e categorias analíticas apropriados é fundamental para a descrição e compreensão dos modos de vida locais" (MPF, 2004: 27). Ainda, não custa lembrar, por exemplo, o fato de muitos Estudos de Impacto Ambiental (EIA) sobre o meio antrópico exigirem métodos e técnicas de pesquisa capazes de identificar as especificidades com as quais os sujeitos se definem e realizam suas territorialidades. Não é por acaso que o Estado brasileiro efetiva suas políticas públicas no cumprimento dos interesses expressos através desses dispositivos legais, por meio de estudos específicos como os desenvolvidos pela equipe de Antropologia do MPF/SC, que mostraremos no decorrer deste trabalho a partir de dois exemplos de situações etnográficas sobre a pesca artesanal. Segundo Oliveira (2004: 16), "o campo precisa ser entendido enquanto uma verdadeira "situação etnográfica" [...], onde os atores interagem com finalidades múltiplas e complexas, partilhando (ainda que com visões e intenções distintas) de um mesmo tempo histórico".

\section{Meio Ambiente, território e espaço social: legislação ambiental versus legislação de populações tradicionais}

A Constituição Federal de 1988 estabelece em seu Art. 225 que "Todos têm direito ao meio ambiente ecologicamente equilibrado, bem de uso comum do povo e essencial à sadia qualidade de vida, impondo-se ao Poder Público e à coletividade o dever de defendê-lo e preservá-lo para as presentes e futuras gerações”. A Carta Magna reserva à compreensão de meio ambiente uma articulação entre homem e natureza, concebendo-o como "bem de uso comum do povo", o que articula as políticas ambientais do Estado com opções de desenvolvimento de acordo com os interesses coletivos da sociedade brasileira (ACSELRAD, 1992).

É interessante pontuar, a partir da perspectiva antropológica, dois aspectos da definição dada ao termo meio ambiente pela $\mathrm{CF} / 1988$ : a) bem de uso comum, patrimônio da humanidade; e b) o fato dele ser produto da relação de grupos humanos com a natureza, o que nos remete à necessidade de verificar 
as especificidades locais, ou seja, não se pode aceitar o meio ambiente como algo abstrato. Nessa perspectiva, concordamos com os argumentos de Diegues (2008a: 85), ao destacar a noção de território como "um elemento importante na relação entre populações tradicionais e a natureza". Prossegue o autor ao enfatizar que é na complexidade das relações dos seres humanos com a natureza - a qual também se apresenta em suas especificidades - que se constitui os meios de subsistência, os meios de trabalho e de produção e os meios de produzir os aspectos materiais das relações sociais que estruturam a sociedade, como as relações de gênero e de parentesco. Logo, o território depende também das relações sociais existentes, pois é compreendido como um espaço de reprodução econômica, das relações sociais e também das representações e do imaginário mitológico das comunidades tradicionais (Ibid.), inclusive as que constituem suas identidades com centralidade na pesca, com destaque para a pesca artesanal. Outrossim, a noção de território abarca outro conceito não menos importante para este estudo, o de espaço social, assim definido como o espaço percebido

[...] entre os indivíduos que participam de um coletivo. É de natureza imaterial, refere-se aos vínculos que traçam as relações entre os indivíduos e a sociedade e que formam o tecido social. Que se representam através de fios invisíveis, de natureza comunicativa que fazem coesão social, é a cola que reúne os homens em lugar comum. Podemos ler diferentes esferas do tecido social, onde se realizam coletivos específicos, cujo objeto de ação é a produção econômica, a organização política e a vida social. (EGLER, 2009: 63).

Nesse sentido, enquanto o espaço construído "pode ser observado em suas formas aparentes e materiais; refere-se aos espaços arquitetônicos e está escrito nos objetos que compõem o processo de ocupação do território" (EGLER, loc. cit.), o espaço social designa "uma categoria analítica hierarquicamente totalizadora, posicionada num patamar acima das disciplinas fragmentadas das Ciências Sociais” (EGLER, 2009: 64). Assim, qualquer modificação no território pode ocasionar ou não impactos negativos sobre os usos sociais do espaço pelas populações tradicionais, alterando as redes sociais que o permeiam.

Meio ambiente, território e espaço social são categorias indispensáveis na tarefa assumida tanto na delimitação quanto na verificação dos impactos sobre o meio antrópico, no sentido de avaliar os diferentes modos de vida tradicional e de organização sociocultural e político-econômica da apropriação territorial local, identificando as relações de interdependência entre as comunidades locais e os recursos naturais. A pertinência do uso dessas categorias se justifica pela própria especificidade do meio antrópico a ser afetado pela ação humana, uma vez que a questão ambiental frequentemente emerge como fonte de disputas territoriais e de acesso a recursos simbólicos e materiais envolvendo diversos atores sociais que, por sua vez, têm diferentes percepções acerca dos usos e sentidos do território. Ao considerar os modos de conceitualização nativos, essa perspectiva corrobora com a ideia de Roy Wagner (2010) sobre a "invenção da cultura" como um processo de criatividade simbólica em que diferentes 
populações locais simultaneamente criam e conceitualizam territórios, lugares, paisagens, entre outros domínios da vida social. Se o território se apresenta conceitualizado a partir do termo pesca artesanal, qualquer estudo sobre o meio antrópico dos espaços sociais onde se processam atividades tradicionais deverá, no mínimo, dar conta do que pede os dispositivos constitucionais consagrados através dos artigos $215^{3}$ e $216^{4}$ da Constituição Federal de 1988, bem como o que exige o supracitado Decreto Federal $n^{0}$ 6.040/2007. Em especial, o Art. 3, item I, afirma que povos e comunidades tradicionais:

\begin{abstract}
São grupos culturalmente diferenciados e que se reconhecem como tais, que possuem formas próprias de organização social, que ocupam e usam territórios e recursos naturais como condição para sua reprodução cultural, social, religiosa, ancestral e econômica, utilizando conhecimentos, inovações e práticas geradas e transmitidas pela tradição. (BRASIL, 2007)
\end{abstract}

Outrossim, como nos mostra Paul E. Little (2002), a apropriação do conceito de territorialidade é ampla e varia de acordo com os diferentes povos tradicionais do/no Brasil. No caso das populações de ribeirinhos da Amazônia e dos pescadores artesanais do litoral, esse autor afirma que "existem formas de apropriação articuladas em função de seus usos, significados e conhecimento das águas. No caso desses últimos, o usufruto coletivo de áreas determinadas estendia-se para além da terra para incluir "territórios marinhos" (LITTLE, 2002: 9). Desse modo, os pescadores artesanais criam territórios, incorporando-os à sua tradição, expressa na pesca artesanal como um modo de vida construído e particular e, portanto, singular de sua própria cultura.

Dadas as considerações gerais acima, vamos à apresentação e análise antropológica de dois exemplos de situações etnográficas vivenciadas em nosso trabalho de campo pericial durante os anos de 2009 a 2010. As informações coletadas foram analisadas a partir de registros documentais (tais como fotos e mapas) e dos relatos das experiências de campo executadas, próprias ao método de cunho etnográfico. Para produzir as imagens dos mapas com as localizações específicas dos ranchos de pesca artesanal, utilizou-se o instrumento de navegação GPS (Global Positioning System), para marcar pontos que se aproximam de "locais inventados" pela tradicionalidade, e o programa Google Earth. O processo de "invenção", seguindo o pensamento de Wagner (2010), corresponde aos sucessivos eventos efetivados pelos sujeitos locais através do tempo e é o que os nativos chamam de pesqueiros (DIEGUES, 2008b). Os pesqueiros registrados durante o trabalho de campo correspondem também a uma certa delimitação do território da pesca tradicional e está relacionado às espécies encontradas no local, movimentos migratórios das espécies, às estações do ano, às condições meteorológicas, a elementos geomorfológicos e aos riscos impostos pelas atividades.

3 Art. 215: "O Estado garantirá a todos o pleno exercício dos direitos culturais e acesso às fontes da cultura nacional, e apoiará e incentivará a valorização e a difusão das manifestações culturais.”

4 Art. 216: "Constituem patrimônio cultural brasileiro os bens de natureza material e imaterial, tomados individualmente ou em conjunto, portadores de referência à identidade, à ação, à memória dos diferentes grupos formadores da sociedade brasileira [...]." 


\section{Situação etnográfica 1: Praia das Cordas}

Trata-se de uma denúncia envolvendo construção irregular na faixa de areia/restinga da Praia das Cordas, no município de Governador Celso Ramos/SC. Em atendimento à solicitação para proceder análise antropológica acerca da tradicionalidade da ocupação de rancho de pesca por pescador profissional e a destinação de seu uso, conforme o disposto instaurado em um inquérito policial civil (IPL), para apurar a autoria e materialidade de crime ambiental de acordo com o supracitado Art. 64 da Lei ${ }^{0}$ 9.605/98, a equipe de Antropologia do MPF/SC realizou vistoria no local em 07 de outubro de 2010. Constatou-se que a ocupação do rancho de pesca (Ponto 02 do Mapa 1; e Fotos 1 e 2) no local destina-se à captura de uma única espécie de peixe, que é a tainha. A pesca da tainha acontece durante o período de inverno, que vai de maio a julho, razão pela qual esse rancho de pesca somente é aberto nesse período, por estar relacionado ao processo migratório das tainhas.

A pesca da tainha está protegida e amparada pela Lei Municipal $\mathrm{n}^{\mathrm{o}}$ 0501/97, que proíbe a prática de surf na praia durante todo o período de pesca da tainha, o que é constatado pela existência de uma placa no interior do rancho de pesca, informando sobre essa proibição em virtude da chegada dos cardumes de tainha (Foto 3). Especificamente sobre a pesca da tainha, trata-se de um evento histórico e sociocultural marcante na afirmação das identidades culturais de pescadores artesanais e para a economia pesqueira, registrada desde o século XVI pelos primeiros cronistas que visitaram as terras brasileiras (SECKENDORFF; AZEVEDO, 2007). 
ACENO, Vol. 3, N. 6, p. 245-263. Ago. a Dez. de 2016. ISSN: 2358-5587.

Cosmologias, territorialidades e políticas de quilombolas e de povos tradicionais (dossiê).

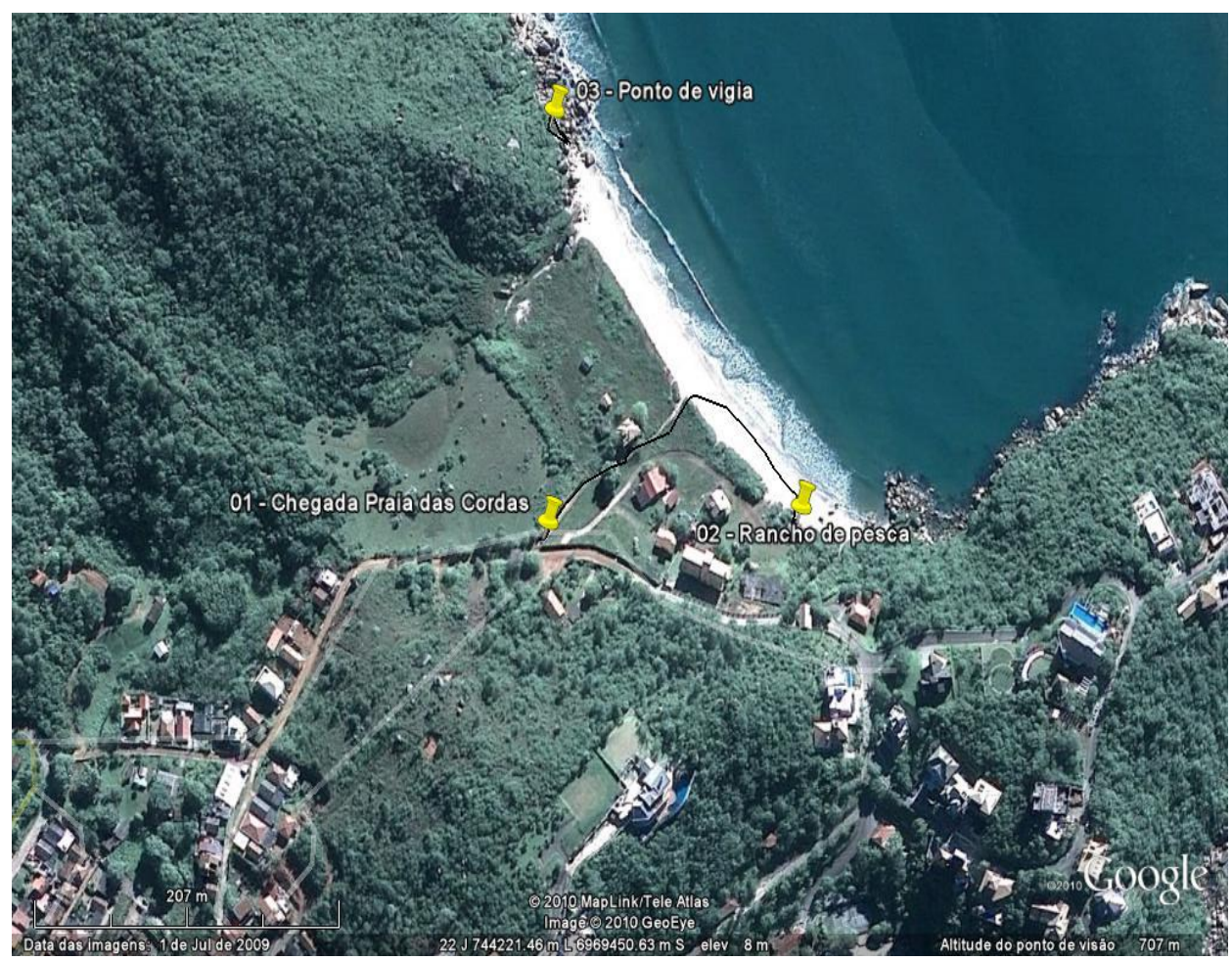

Mapa 1: o ponto 02 mostra a localização do rancho de pesca.

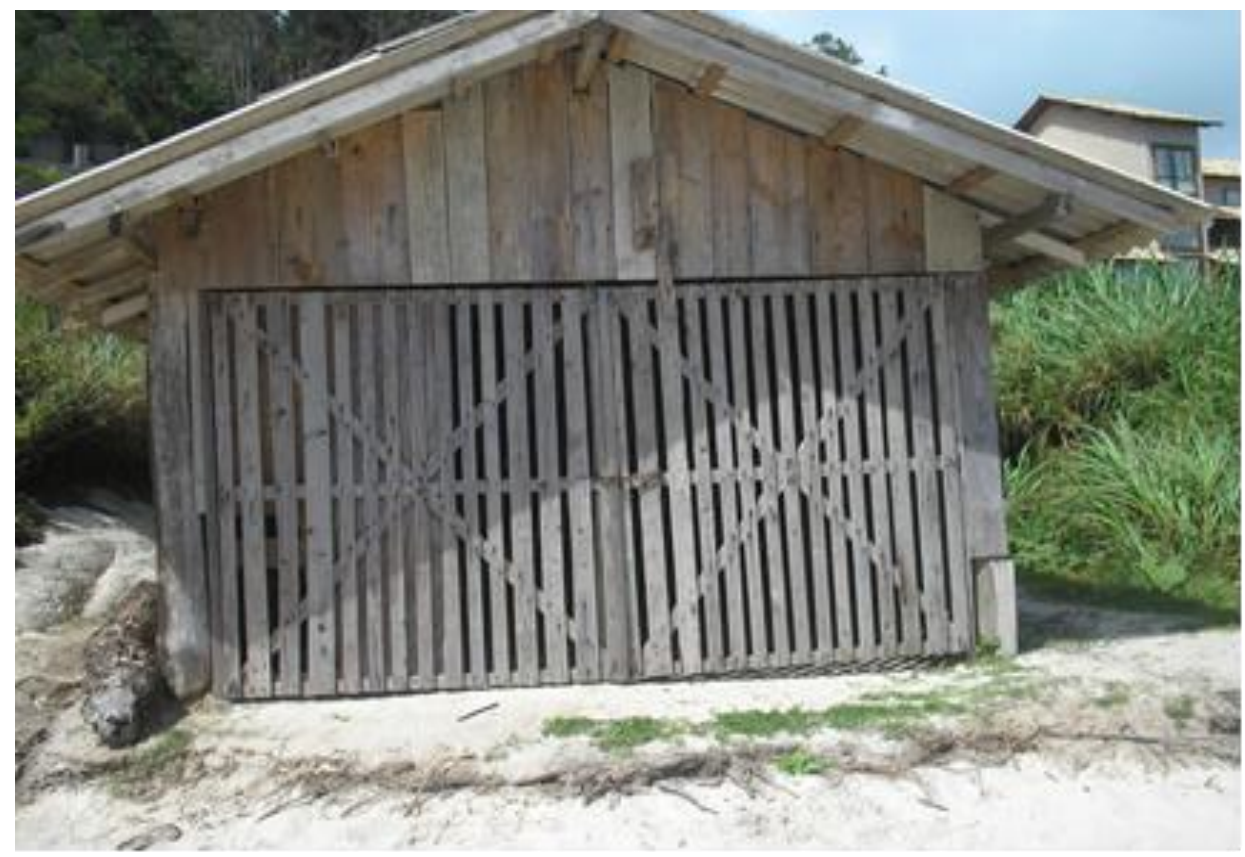

Foto 1: imagem frontal do rancho de pesca.

Foto tirada durante a vistoria em 07/10/2010.

Crédito: equipe da Assessoria Pericial Antropológica do MPF/SC. 


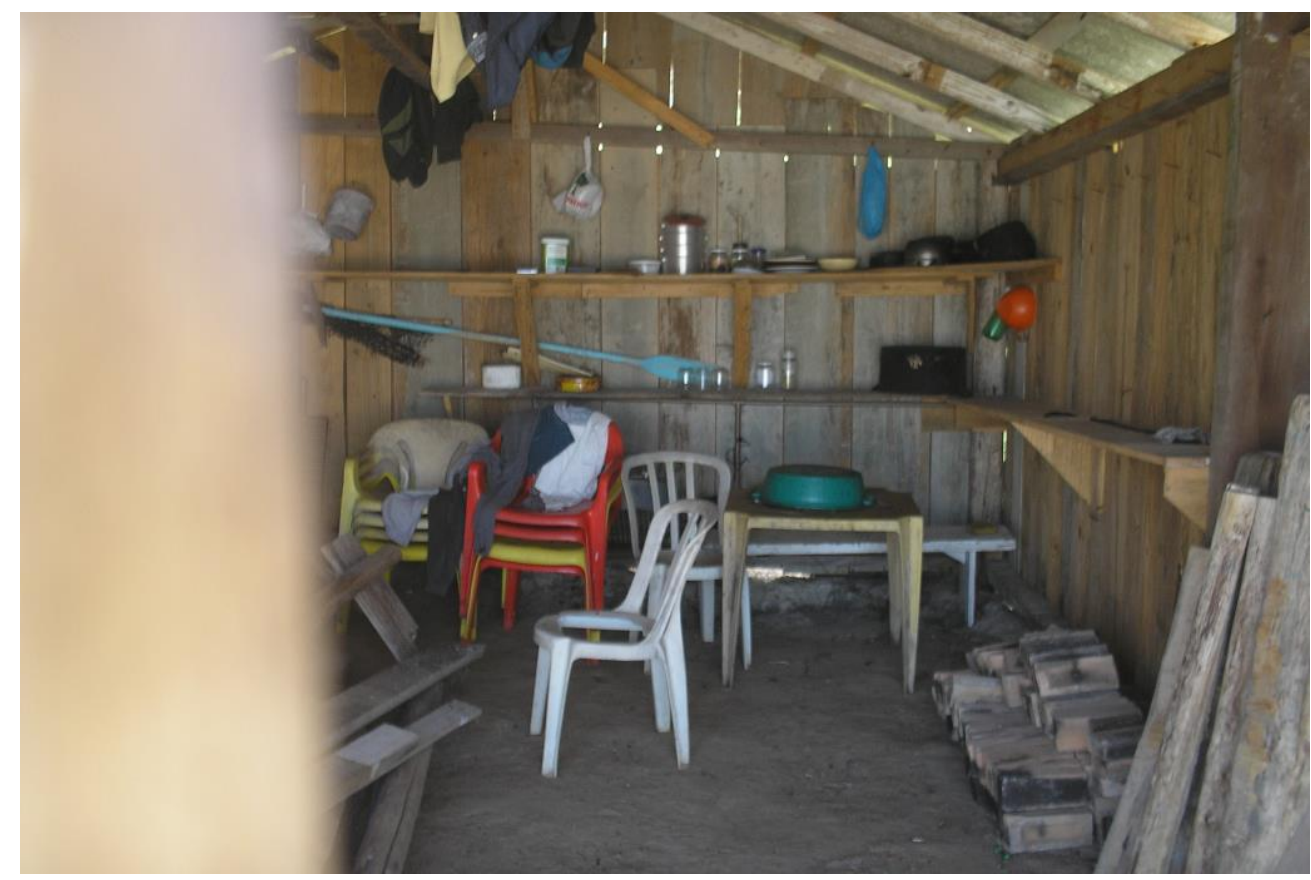

Foto 2: interior do rancho de pesca.

Foto tirada durante a vistoria em 07/10/2010.

Crédito: equipe da Assessoria Pericial Antropológica do MPF/SC.

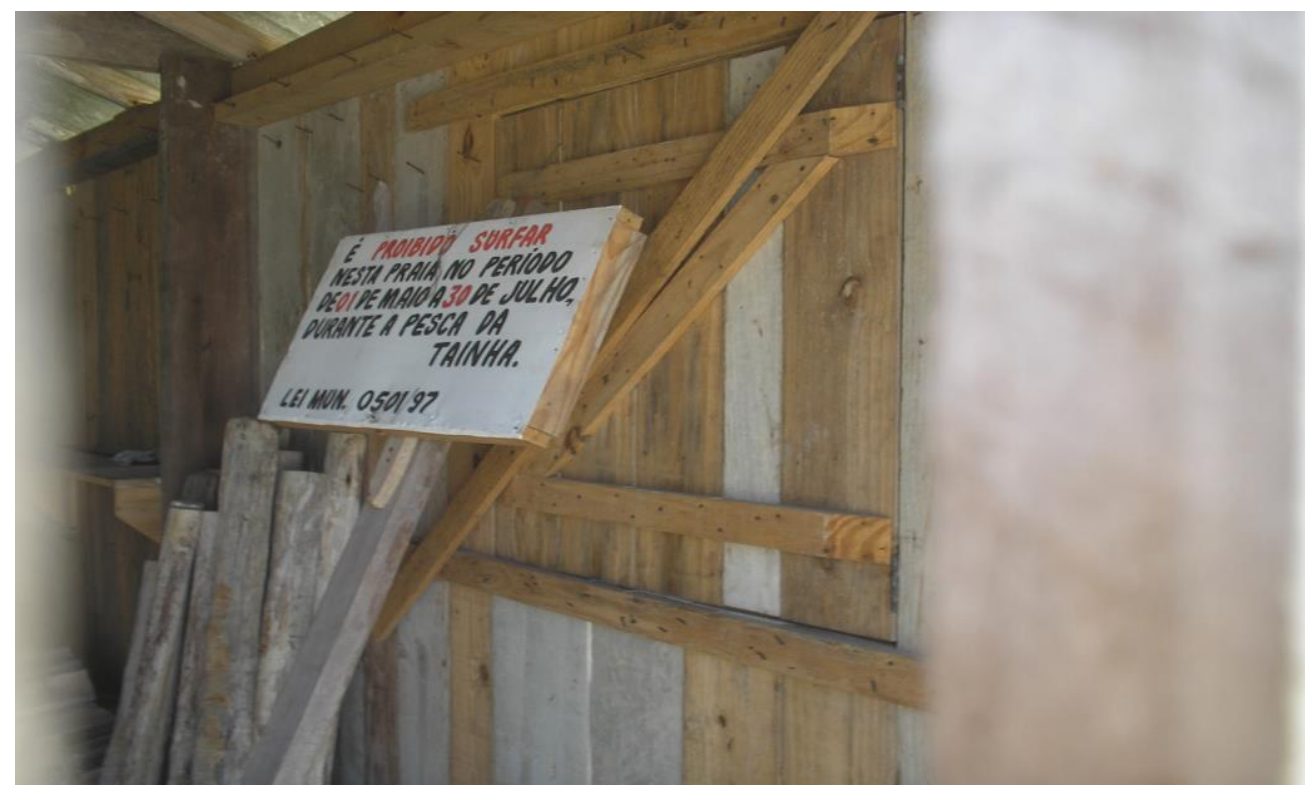

Foto 3: placa informando a proibição da prática de surf durante a safra da tainha. Foto tirada durante a vistoria em 07/10/2010.

Crédito: equipe da Assessoria Pericial Antropológica do MPF/SC.

Outro marcador da tradicionalidade da área se evidenciou pela existência de um "ponto de vigia" no local (ver Ponto 3 do Mapa 1 acima, bem como a Foto 
4 abaixo). Vinda da Lagoa dos Patos, no Estado do Rio Grande do Sul, os cardumes de tainha saem em busca de águas mais quentes para desovar, distribuindo-se em águas tropicais e subtropicais, especialmente em regiões costeiras e estuarinas (SECKENDORFF; AZEVEDO, 2007: 2-3). De acordo com os relatos de pescadores locais, o horário que a tainha chega à costa é por volta das 4 horas da manhã. É também nesse horário que os chamados olheiros, vigias ou espias sobem os costões da praia para observar a chegada e informar aos pescadores que aguardam na praia. $\mathrm{O}$ espia geralmente acena e aponta com um pano o local exato do cardume, que se caracteriza por uma grande mancha vermelha, e os outros pescadores artesanais aguardam na praia esse sinal para colocarem as canoas no mar. Eles ainda esperam que o pescador vigia lhes informe o momento exato para iniciar a pesca. São três silvos, o primeiro é para preparar a embarcação; o segundo, colocar a canoa no mar; e o terceiro, lançar a rede para a captura das tainhas.

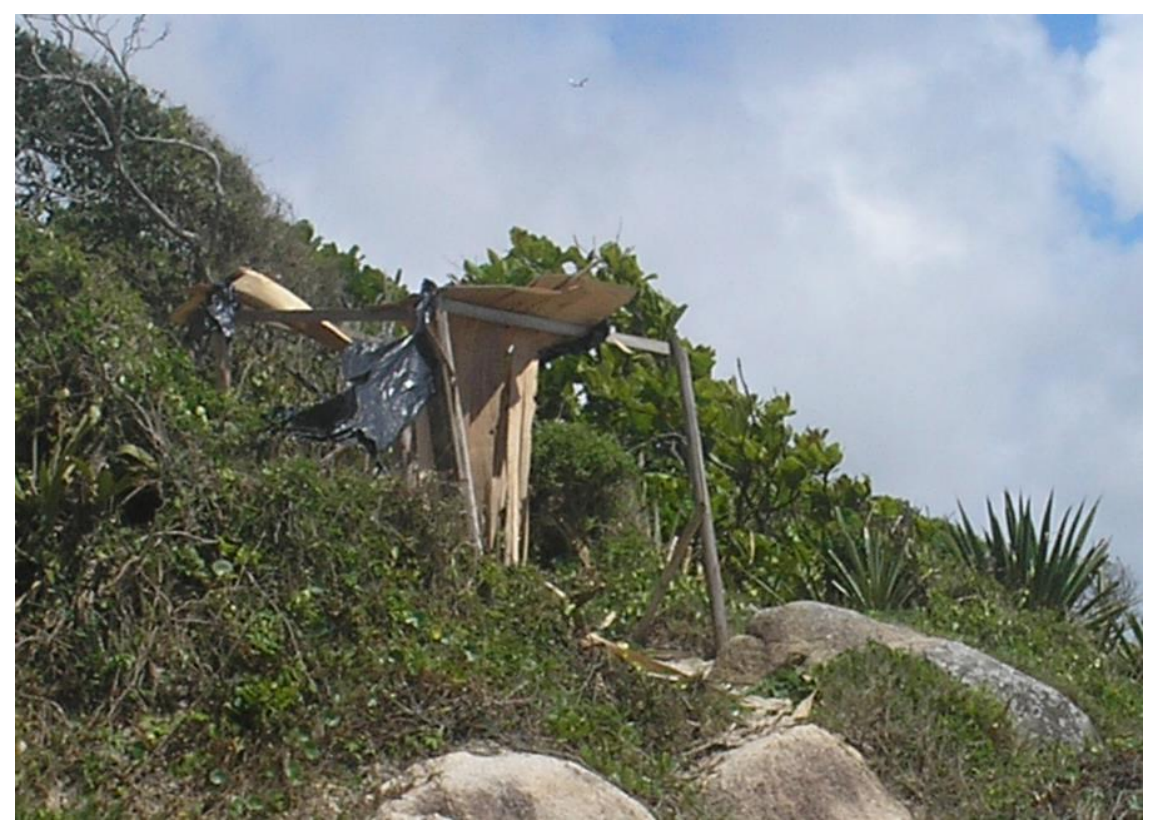

Foto 4: ponto de vigia. Foto tirada durante a vistoria em 07/10/2010. Crédito: equipe da Assessoria Pericial Antropológica do MPF/SC.

Durante a vistoria realizada também entrevistamos o Sr. Valdemar5, com sua esposa e algumas pessoas que encontramos próximo à localização do rancho de pesca. Valdemar é pescador há cerca de 30 anos, ofício que aprendeu desde criança, quando participava das atividades de pesca realizadas por parentes e outros moradores da região: 


\begin{abstract}
"A gente pesca lá e traz para a família comer, né? Por exemplo, se eu matar duzentas tainhas no dia, aí eu tiro a metade, a metade é minha. Daí a outra metade eu divido para as outras dez pessoas que ficam. Das minhas cem, eu dou umas vinte: para o patráo da canoa e os remeiros e o vigia que fica lá na pedra. Na verdade para mim vai sobrar umas cinquenta ou sessenta tainhas. (...) Não, naquela praia lá não. Tem um outro filho que pesca, mas é em um outro lugar. Meus avós toda vida tiveram rede aqui perto de Maruí (?). Meu pai morreu com oitenta anos e até os setenta anos pescava de patrão nas canoas dele, não na minha. Então nós pegamos isso como tradição [...].” (Valdemar)
\end{abstract}

$\mathrm{Na}$ entrevista ficou claro que o pescador entende os riscos atuais para a manutenção da referida atividade tradicional, inclusive pelo fato dele ser o responsável pela organização dos eventos, o que tem a posse das baleeiras e demais petrechos de pesca, e recebe licença dos órgãos públicos para a realização da prática tradicional de pesca.

A denúncia se deu em virtude dos pescadores, conforme faziam todos os anos, não terem retirado o rancho após as atividades de pesca da tainha. Quando inquirido sobre esse assunto, respondeu-nos o pescador:

\begin{abstract}
"Eu fazia todo ano: pescava os dois meses e depois tirava, aí os rapazes que pescam comigo disseram assim [reproduzindo o discurso] 'Valdemar, assim não vai dá para gente continuar pescando porque só tem prejuízo. Todo ano você gasta tudo com material para o rancho, é só fazer desmanchar, fazer desmanchar e a gente não tem onde guardar, para trazer para cá era longe...' Aí resolvemos fazer e deixar lá, mas não é para ninguém usar fora da pesca da tainha. Quando acaba os dois meses da tainha, eu fecho tudo com o cadeado, tali a chave ó? Lá não entra ninguém, a não ser que eles invadam para entrar." (Valdemar)
\end{abstract}

Diante desses argumentos, indagamos que se os órgãos públicos assumissem a responsabilidade e os custos da montagem e desmontagem dos ranchos utilizados para a pesca da tainha, eles concordariam e ouvimos como resposta:

\footnotetext{
“Ah! Seria uma boa. Porque aí eu não teria prejuízo né? Porque se for depender de todo ano fazer e desmanchar, todo ano comprar material, fazer e desmanchar, aí não dá porque eu vou ter que pô dinheiro do bolso para manter. Eu trabalho com a pesca desde os doze anos e mesmo aposentado eu nunca parei de pescar, também porque a gente se aposenta com um salário mínimo e aí não dá.”(Valdemar)
}

\title{
Situação etnográfica 2: Praia da Tapera
}

Os ranchos de pesca constituem-se em um tema bastante emblemático em Florianópolis/SC, recebendo encaminhamentos diferenciados a partir dos Procuradores da República que cuidam dos processos judiciais. Por exemplo, também acompanhamos os ranchos de pesca construídos na Praia da Tapera (Fotos 5 e 6 abaixo), localizada no município de Florianópolis, pois existe um antigo processo de ocupação naquela região. 


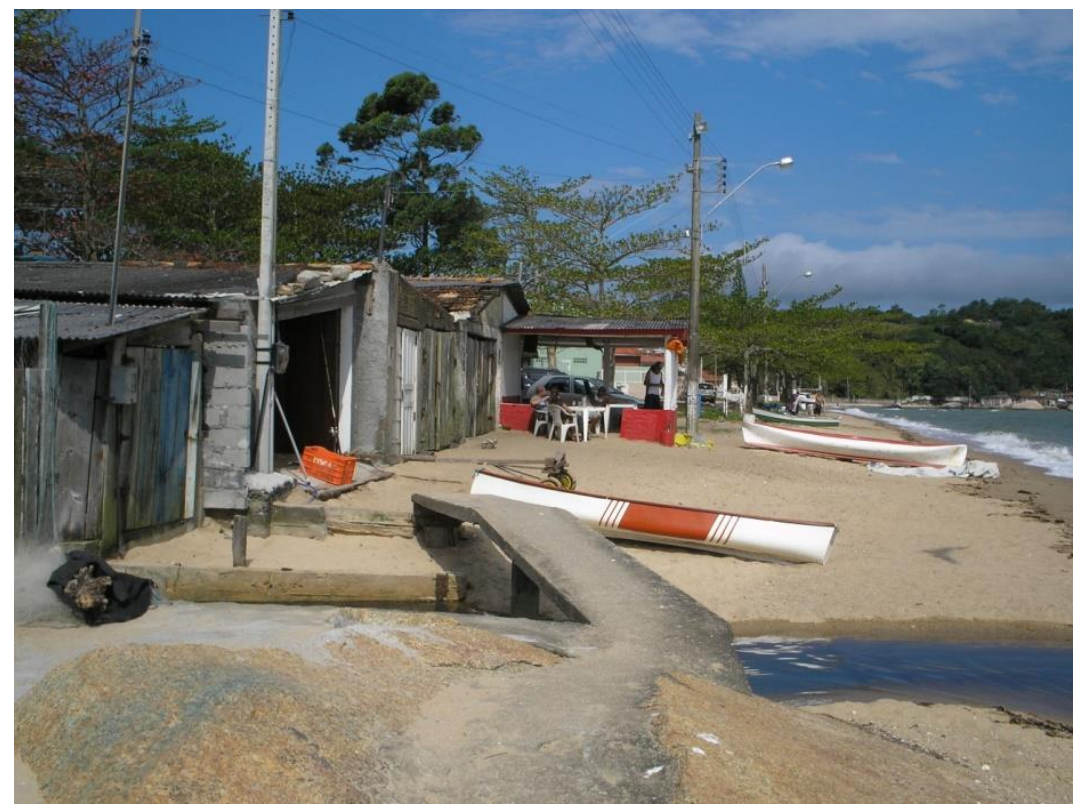

Foto 5: ranchos de pesca construídos na Praia da Tapera. Foto tirada em 13/06/2009.

Crédito: equipe da Assessoria Pericial Antropológica do MPF/SC.

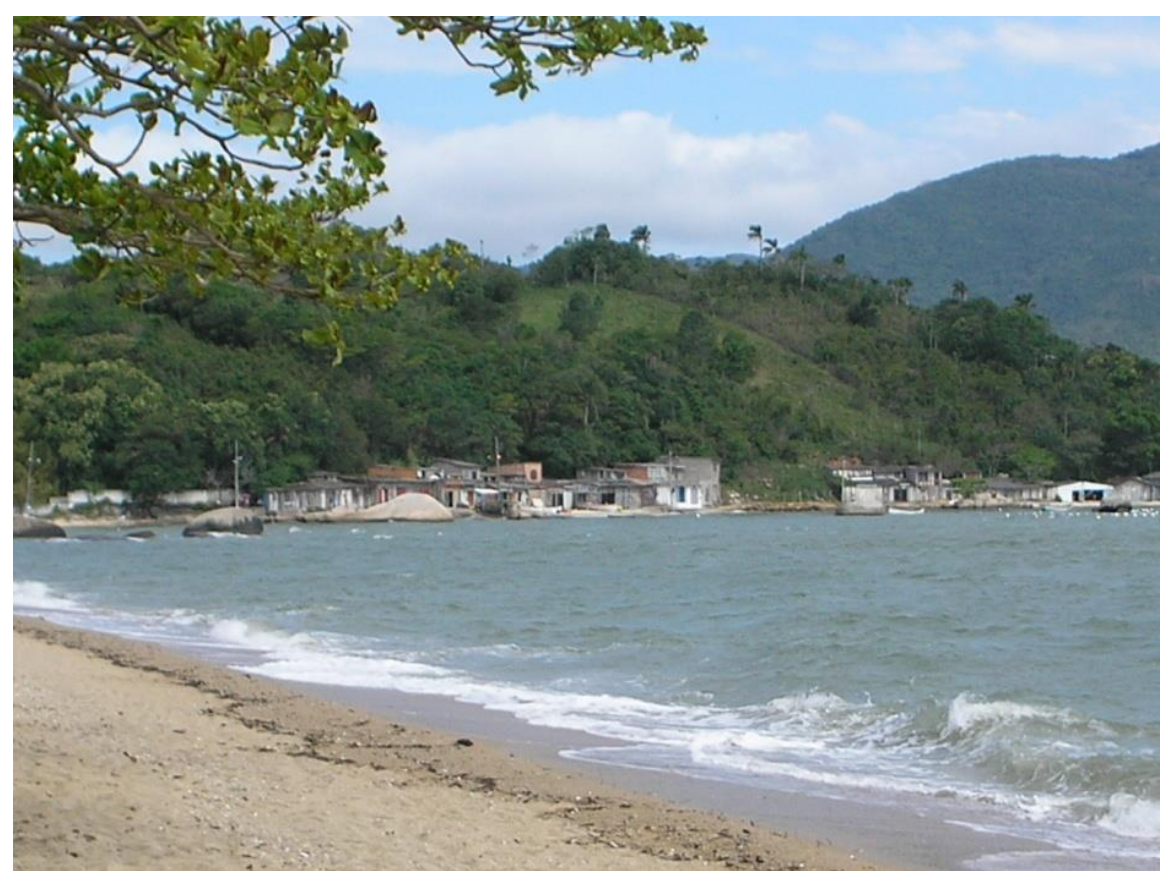

Foto 6: os mesmos ranchos de pesca, vistos em outra perspectiva. Foto tirada em 13/06/2009.

Crédito: equipe da Assessoria Pericial Antropológica do MPF/SC.

Esta situação de perícia também partiu de uma denúncia sobre ocupação irregular na Praia da Tapera. No intuito de verificar se a ocupação desordenada da praia consiste em um problema habitacional e qual a relação efetiva dos ranchos de pesca lá localizados com a atividade de pesca dos ocupantes, primeiramente foi solicitado, em setembro de 2009, à equipe de Antropologia do MPF/SC a elaboração de questionários com perguntas contendo elementos que ligassem de forma consistente a pesca artesanal à condição de 
tradicionalidade dessa prática e ao patrimônio cultural, sobretudo, com a necessária articulação entre patrimônio cultural material e imaterial. Segundo o Ministério Público Federal,

\begin{abstract}
o item "c" do Art. $6^{\circ}$ da Resolução Conama 001/86 (Conselho Nacional do Meio Ambiente) estabelece a necessidade de considerar bens culturais das comunidades. Porém, em sua maioria, os diagnósticos não trabalham com conceitos mais contemporâneos, formulados no âmbito das políticas públicas de preservação cultural. Embora nem sempre considerados, já são comuns [apenas] os levantamentos do potencial arqueológico. Ressaltamos a importância de que em todos os casos se realizem estudos dos significados dos bens culturais para as populações locais, grupos socioculturais e sociedades indígenas. Considerando os Arts. 215 e 216 da Constituição Federal, a clara valorização da diversidade cultural brasileira e a amplitude dos bens culturais considerados no conceito de patrimônio cultural permitem afirmar que esse conceito não encontra satisfatória correspondência nos estudos, apesar das orientações do Instituto do Patrimônio Histórico e Artístico Nacional (IPHAN). (MPF, 2004: 28)
\end{abstract}

O questionário foi debatido em uma reunião coordenada pelo Procurador da República responsável pelo caso, contando com a participação da equipe de Antropologia do MPF/SC, do Procurador do município e de representantes da Assistência Social do município de Florianópolis, do Instituto de Planejamento Urbano de Florianópolis (IPUF), do Instituto Brasileiro do Meio Ambiente e dos Recursos Naturais Renováveis (IBAMA) e do Ministério da Pesca e Aquicultura em Santa Catarina - MPA/SC. A reunião teve como objetivo a discussão de questionários para o levantamento de informações sobre os moradores dos ranchos de pesca situados na Praia da Tapera. Entretanto, essa reunião foi um pouco tumultuada, porque alguns desses órgãos públicos questionaram a abordagem das perguntas, considerando as questões sobre o perfil socioeconômico muito "invasivas". Em diversos momentos, o diálogo entre os distintos órgãos públicos era complicado. Por isso, nessa situação etnográfica a necessidade de elaboração de um laudo pericial antropológico acabou transformando-se em "cadastramento de pescadores", porquanto o Procurador da República que acompanhou esse caso ainda considerou desnecessário o questionário feito pela equipe de Antropologia do $\mathrm{MPF} / \mathrm{SC}$, preferindo o elaborado pelo MPA/SC, que não continha nenhuma pergunta que pudesse revelar diversos aspectos da ocupação tradicional dos ranchos de pesca localizados na Praia da Tapera.

Posteriormente, o processo judicial voltou à Assessoria Pericial Antropológica do MPF/SC em 2010, desta vez para proceder análise dos questionários preenchidos do "Cadastro dos Ocupantes de Ranchos da Praia da Tapera”, feito pelo referido MPA/SC, o qual emitiu nota técnica definindo o termo ocupação irregular como sendo o que vincula "[...] à ausência de registro [do pescador] na Superintendência Federal do Ministério da Pesca e Aquicultura - MPA". Esse argumento se constituiu na principal referência de informação, parâmetro posto como fundamental para a classificação das atividades pesqueiras em área considerada "bem de uso comum do povo" (Art. 225 da CF/1988). Contudo, segundo o Art. 26 do Decreto-Lei no 221, de 28 de fevereiro de 1967, "pescador profissional é aquele que, matriculado na 
repartição competente segundo as leis e regulamentos em vigor, faz da pesca sua profissão ou meio principal de vida". Do ponto de vista antropológico, consideramos a classificação do MPA/SC insuficiente para garantir os legítimos interesses nas ocupações do local, devendo a aplicação desse termo, ocupação irregular, ser justificada a partir da apresentação de dados etnográficos.

Verificou-se que dados fundamentais para a identificação dos efeitos tradicionais da pesca artesanal não foram preenchidos nos questionários, como a profissão dos pais, a identificação das pessoas que utilizam o rancho, a profissão destas e as práticas de uso das atividades de pesca. Para além da verificação de outros aspectos da ocupação, como a tradicionalidade, mesmo as respostas contidas nos questionários, inclusive aquela sobre a situação do vínculo estabelecido com o MPA, não foram suficientes para preencher todos os critérios de identificação de pescador profissional a ocupar rancho de pesca. Nem mesmo a simples titulação da carteira de pescador comprovou a condição de pescador profissional, devido à necessidade de participação do Ministério do Trabalho e Emprego - MTE (para o controle do PIS $^{6}$ e CAGED7) e do INSS ${ }^{8}$ (para verificação de contribuição previdenciária na condição de pescador profissional) nesse procedimento burocrático. Ainda, os dados coletados através do instrumento questionário, feito pelo $\mathrm{MPA} / \mathrm{SC}$, não foram analisados nem receberam um tratamento estatístico, inclusive não se apresentando na forma de gráficos e tabelas, para a visualização e análise dos mesmos. Diante dessa constatação, a equipe de Antropologia do MPF/SC elaborou novo parecer técnico para o Procurador da República, enfatizando que a tradicionalidade de uma comunidade pesqueira em determinado território ocupado se verifica mediante a realização de perícia antropológica [grifo nosso], a fim de se proceder à adequada caracterização dos modos de vida dos pescadores que de fato realizam atividades tradicionais. Dessa forma, os pescadores garantem, a partir dessas atividades, a reprodução sociocultural da pesca artesanal e a sobrevivência familiar como única ou principal fonte de renda.

Os questionários são ferramentas de análise quantitativas podendo complementar a perícia antropológica, porquanto concomitantemente à etapa quantitativa do levantamento, também é de suma importância a utilização de ferramentas qualitativas, tais como entrevistas e conversas com os pescadores, a fim de identificar os efeitos da tradicionalidade das práticas de pesca artesanal, as formas pelas quais a pesca artesanal se desenvolve, os modos de vida locais, suas representações culturais e vínculos sociais. Fonseca (2008) aponta para os benefícios da complementaridade dos dois métodos, ou seja, a combinação entre os métodos quantitativos e qualitativos pode ser capaz de melhorar a qualidade dos resultados de trabalhos de investigação que envolvam estudos de um mesmo fenômeno, de modo que "o resultado final seja cada vez

6 Abreviatura para Programa de Integração Social, referente à contribuição tributária de caráter social dada pelo governo federal com o objetivo de financiar o pagamento do seguro-desemprego, abono e participação na receita dos órgãos e entidades para os trabalhadores de empresas públicas e privadas.

7 Abreviatura para Cadastro Geral de Empregados e Desempregados, em que o Ministério do Trabalho e Emprego deve controlar as admissões e demissões de empregados que ocorrem no país sob o regime da Consolidação das Leis do Trabalho (CLT).

8 Abreviatura para Instituto Nacional do Seguro Social, órgão público federal responsável pelos pagamentos das aposentadorias e demais benefícios dos trabalhadores brasileiros que contribuem com a previdência social. 
mais isento, mais sólido e transparente, mais completo, resultando assim num melhor e maior conhecimento dos temas que nos propormos investigar" (FONSECA, 2008: 13).

\section{O “ambientalismo oficial” dos agentes estatais nas práticas de criminalização dos pescadores artesanais}

Nas duas situações etnográficas a ação é orientada por um pressuposto: a realização de uma irregularidade contra o meio ambiente. A partir desse pressuposto, o trabalho da polícia ambiental se constitui na identificação do responsável pela realização da irregularidade e pela caracterização dos elementos que confirmam o ato criminoso. Esse processo acaba tornando-se perverso e descontextualizado, pois o pescador não é visto pela realização da prática artesanal, mas a partir de uma atividade criminal contra o meio ambiente.

Os processos judiciais das duas situações etnográficas iniciam seguindo o mesmo percurso, isto é, os agentes da polícia ambiental do Estado de Santa Catarina realizam, com base na legislação ambiental, autuação dos proprietários dos ranchos de pesca e encaminham o documento aos órgãos competentes do Poder Judiciário que, de posse desses dados, oferecem denúncia contra os proprietários dos ranchos de pesca. O percurso tomado pelos agentes policiais se ancora na interpretação de que todos os grupos humanos são iguais. Desse modo, porque não há diferença na organização dos grupos sociais, inclusive na maneira como se relacionam com o ambiente desde um ponto de vista legal deslocado de argumentos empíricos fundamentais e distante da necessária interpretação da lei frente a outros dispositivos legais, mesmo os que estão consagrados na Constituição Federal de 1988, é possível classificar criminalmente os responsáveis pelos ranchos de pesca construídos e a forma como desenvolvem suas territorialidades.

Em ambas as situações etnográficas, apesar de não termos competência técnica para analisarmos os discursos apresentados nos autos pelos "agentes autuantes" no que diz respeito à interpretação feita sobre as especificidades dos meios físicos e bióticos, o que deve ser feito por profissionais dessas áreas, por outro lado, desde as Ciências Sociais, em especial a Antropologia, destacamos dois pressupostos encontrados na configuração desse drama social: a) os grupos humanos estão dissociados do meio ambiente e colocados em rivalidade com o mesmo; e b) os grupos humanos são iguais, de modo que a interpretação dos efeitos sobre o meio antrópico é operada pela eleição dos significados tratados no campo das transgressões legais. Esses dois pressupostos representam a tônica do "ambientalismo oficial" (VIVEIROS DE CASTRO; ANDRADE, 1988), que se pauta em um discurso logocêntrico em que o saber científico se sobrepõe ao saber local ou tradicional (LEFF, 2001a, 2001b, 2004). Para Leff (2001b), o 
conhecimento ambiental deve convergir entre tradição e conservação ambiental, por meio de um saber ambiental que exceda as "ciências ambientais":

\begin{abstract}
O saber ambiental excede as "ciências ambientais", constituídas como um conjunto de especializações surgidas das incorporações dos enfoques ecológicos às disciplinas tradicionais - antropologia ecológica; ecologia urbana; saúde, psicologia, economia e engenharia ambientais - e se estende além do campo de articulação do campo das ciências [...] para abrir-se ao terreno dos valores éticos, dos conhecimentos práticos e dos saberes tradicionais. (LEFF, 2001b: 145)
\end{abstract}

Nesse sentido, a operação da criminalização da pesca artesanal é realizada pela afirmação de um princípio binário, homem versus natureza, em que tanto o homem quanto a natureza são vistos como entes genéricos, posição esta não sustentada pelos sujeitos denunciados e há muito tempo abandonada pelas Ciências Sociais (Cf. VIVEIROS DE CASTRO, 2007) e pela Constituição Federal Brasileira de 1988. Diegues (2008b), ao tratar do modelo de criação de áreas naturais protegidas, menciona que a criação desses espaços se embasa em uma concepção específica da relação homem/natureza na qual "a única forma de proteger a natureza era afastá-la do homem [...]." (DIEGUES, 2000: 17). Tratase, para esse autor, de um "mito moderno" que se funda na existência de um mundo natural selvagem, intocado, porquanto destaca a importância da participação das populações tradicionais para o estabelecimento e preservação das áreas protegidas. Conforme escreve Hofbauer (2006: 317) ao reportar a um trabalho de Goody (1987) que se dá a partir de reflexões de Max Weber, é porque os assuntos sociais são tratados através de regras abstratas e códigos legais, os fenômenos da vida social acabam sendo burocratizados e racionalizados.

\title{
Considerações finais
}

A tradicionalidade da ocupação de ranchos de pesca em determinado território verifica-se através da realização de perícia antropológica para caracterizar os modos de vida dos pescadores locais. Os laudos periciais produzidos mostraram que a ação do Ministério Público Federal é processada em um contexto de marginalização da tradicionalidade, de conflitualidade que perpassa a legislação ambiental, os diversos órgãos públicos9 e o código penal, os quais operam sem considerar as especificidades da pesca artesanal. As denúncias e as investigações desses órgãos recorrentemente não consideram os efeitos das identidades étnicas em jogo e pautam-se em um conceito de meio ambiente que coloca em risco os interesses das populações tradicionais, registrados e garantidos na legislação desde a Constituição Federal de 1988. 
Os fatos apresentados aqui nos permitem concluir que existem responsabilidades dos órgãos públicos, "escondidos" nesse processo de criminalização da pesca artesanal, inclusive daqueles criados especificamente para a sua proteção. Tal conclusão se verifica na falta de fiscalização dos mencionados órgãos públicos em relação aos procedimentos de produção e realização das atividades de pesca artesanal. Por outro lado, os argumentos destacados informam também sobre a disposição dos pescadores em fazer cumprir os dispositivos legais, sem desrespeitar os "princípios tradicionais". Os eventos processados nas duas situações etnográficas, ao mesmo tempo em que informam sobre a realização das atividades tradicionais de pesca artesanal que deve ser protegida, mostram também como se configuram ali, de forma objetiva, a representação do que seja meio ambiente, afastando a possibilidade de prender a produção de significados das tradicionalidades e territorialidades impactadas à burocracia, que insiste em tratar os grupos humanos como iguais, submetidos às mesmas relações com os outros elementos da natureza e, portanto, em rivalidade com eles.

Outro argumento que merece ser destacado, ainda que não seja objeto deste presente trabalho, se refere à relação que várias territorializações fazem entrecruzar, como os efeitos das relações entre humanos e não humanos, onde os espaços marinhos estão diretamente imbricados com os espaços terrestres, mesmo aqueles sob processo de ocupação histórica. Prova desse argumento ganha significado nos estudos históricos sobre os procedimentos de ocupação do litoral sul do Brasil, principalmente em áreas de fortificações ligadas ao sistema defensivo da Ilha de Santa Catarina, onde também se realizam atividades de pesca artesanal. Essas fortificações remetem ao processo de ocupação histórica e defesa do território brasileiro contra as invasões espanholas a partir do século XVIII, sendo também referências cotidianamente interpretadas nas ações dos moradores descendentes das primeiras famílias não indígenas a ocupar a região. Inclusive é nesse contexto histórico que se nos apresenta a utilização de armações baleeiras nas atividades de pesca nos territórios ocupados de modo tradicional em torno de regiões de fortificações (Cf. SANTOS, 1999; MOSIMANN, 2003).

\section{Bibliografia}

ACSELRAD, Henri. Cidadania e Meio Ambiente. In.: ACSELRAD, Henri (Org.). Meio Ambiente e Democracia. Rio de Janeiro: IBASE, 1992.

BARRETTO FILHO, Henyo. A ambientalização dos conflitos sociais; participação e controle público da poluição industrial. Comunidade Virtual de Antropologia, n. 29, 2005. Disponível em: <http://www.antropologia.com.br/res/res29_1.htm\#top>. Acesso em: 20 nov. 2016. Resenha. 
BRASIL. Lei $\mathrm{n}^{\circ}$ 9.605, de 12 de fevereiro de 1998. Dispõe sobre as sanções penais e administrativas derivadas de condutas e atividades lesivas ao meio ambiente e dá outras providências. Diário Oficial da União, Brasília, DF, n ${ }^{0} 31$, 13 fev. 1998. Seção 1, p. 1. Disponível em: <http://www.planalto.gov.br/ccivil_03/leis/L9605.htm>. Acesso em: 20 nov. 2016.

BRASIL. Decreto $\mathrm{n}^{0}$ 6.040, de 7 de fevereiro de 2007. Institui a Política Nacional de Desenvolvimento Sustentável dos Povos e Comunidades Tradicionais. Diário Oficial da União, Brasília, DF, $\mathrm{n}^{0}$ 28, 8 fev. 2007. Seção 1, p. 316-317. Disponível em: <http://www.planalto.gov.br/ccivil_03/_ato20072010/2007/decreto/d6040.htm>. Acesso em: 20 nov. 2016.

DIEGUES, Antonio Carlos S. As populações tradicionais: conceitos e ambigüidades. In.: O mito moderno da natureza intocada. $6^{\mathrm{a}}$ ed. ampliada. São Paulo: Hucitec, NUPAUB/USP, 2008a, p. 77-100.

DIEGUES, Antonio Carlos S. O mito moderno da natureza intocada. $6^{\mathrm{a}}$ ed. ampliada. São Paulo: Hucitec, NUPAUB/USP, 2008b.

EGLER, Tamara T. C. Espaço social e política urbana global. In.: EGLER, Tamara T. C.; POGGIESE, Hector (Orgs.). Otro desarrollo urbano: ciudad incluyente, social y gestion democratica. Buenos Aires: Clacso, 2009.

FONSECA, Jaime Raúl S. Os Métodos Quantitativos na Sociologia: dificuldades de uma metodologia de investigação. In: VI Congresso Português de Sociologia - Mundos Sociais: saberes e práticas. Universidade Nova de Lisboa, Lisboa, 25 a 28 junho de 2008, $\mathrm{n}^{0} 346$, p. 01-18, 2008.

GOODY, Jack. A lógica da escrita e a organização da sociedade. Lisboa: Edições 70, 1987.

HOFBAUER, Andreas. Uma história de branqueamento ou o negro em questão. São Paulo: Editora UNESP, 2006.

LEFF, Enrique. Epistemologia ambiental. São Paulo: Cortez, 2001a.

LEFF, Enrique. Saber Ambiental: sustentabilidade, racionalidade, complexidade, poder. Petrópolis: Vozes, 2001b.

LEFF, Enrique. Racionalidad ambiental: la reapropiación social de la naturaleza. México: Siglo XXI Editores, 2004. 509 p.

LITTLE, Paul E. Territórios sociais e povos tradicionais no Brasil: por uma Antropologia da Territorialidade. Série Antropologia, n. 322. Brasília: Departamento de Antropologia da Universidade de Brasília (DAN/UnB), 2002.

LOPES, José Sérgio L. Sobre processos de "ambientalização" dos conflitos sociais e sobre dilemas da participação. Horizontes Antropológicos, Porto Alegre, ano 12, n. 25, p. 31-64, jan./jun. 2006.

MINISTÉRIO PÚBLICO FEDERAL, Deficiências em Estudos de Impacto Ambiental: síntese de uma experiência. Brasília: Ministério Público Federal, $4^{\mathrm{a}}$ 
Câmara de Coordenação e Revisão: Escola Superior do Ministério Público da União, 2004. 48p.

MOSIMANN, João Carlos. Ilha de Santa Catarina, 1777-1778: a invasão espanhola. Florianópolis: Edição do Autor, 2003.

OLIVEIRA, João P. Pluralizando tradições etnográficas: sobre um certo mal estar na antropologia. In.: LANGDON, Esther J.; GARNELO, Luíza (Orgs.). Saúde dos Povos Indígenas: reflexões sobre uma antropologia participativa. Rio de Janeiro: Contra Capa, Associação Brasileira de Antropologia, 2004, p. 10-28.

SANTOS, Sarita. Querida Armação de Itapocorói: originais de "Picucho Santos”. Blumenau: Editora e Gráfica Odorizzi, 1999.

SECKENDORFF, Roberto W. von; AZEVEDO, Venâncio G. Abordagem Histórica da Pesca da Tainha Mugil platanus e do Parati Mugil curema (peciformes: mugilidae) no litoral norte do Estado de São Paulo. In: Série Relatórios Técnicos. São Paulo: Instituto de Pesca da Secretaria de Agricultura e Abastecimento, Agência Paulista de Tecnologia dos Agronegócios, $n^{0}$ 28, p. 1-8, jun./2007.

VIVEIROS DE CASTRO, Eduardo; ANDRADE, Lúcia. Obras do destino: o ambientalismo oficial. In.: Tempo e presença. São Paulo, CEDI, n. 330, p. 6-8, 1988.

VIVEIROS DE CASTRO, Eduardo. A natureza em pessoa: sobre outras práticas de conhecimento. In.: Entre visões do Rio Babel: conversas sobre o futuro da Bacia do Rio Negro. Manaus: Instituto Socioambiental, Fundação Vitória Amazônica, 2007.

WAGNER, Roy. A Invenção da Cultura. São Paulo: Cosac Naify, 2010.

Recebido em 23/11/2016. Aprovado em 11/12/2016. 